\title{
The Geneva Risk and Insurance Review 2011: A Catalyst for New Research Ideas
}

\author{
Jean-François Outreville \\ HEC Montreal, 3000 cote Sainte Catherine, Montreal, Quebec H3T 2A7, Canada.
}

The purpose of this paper is to review and summarise the papers published in The Geneva Risk and Insurance Review in 2011. Asymmetric information and the performance of insurance markets are important issues that are regularly discussed in the review, but this volume also illustrates particularly well one of the missions of the review: to publish "new and innovative ideas".

The Geneva Papers (2012) 37, 594-602. doi:10.1057/gpp.2012.30

Keywords: risk and uncertainty; asymmetric information; insurance

\section{Introduction}

The Geneva Risk and Insurance Review (GRIR) aims to publish high-quality papers that advance our understanding on the technical aspects of risk and insurance economics, especially new and innovative ideas and papers from related disciplines. During the past few years, the issue of adverse selection, asymmetric information and moral hazard has been examined in one out of five papers published. ${ }^{1}$ This was again validated in 2011. These papers are of particular relevance for insurers and the proper functioning of insurance markets, but the scope of the review is broader, and other papers highlight how applied research in risk theory could have important implications for the insurance industry.

A descriptive quantitative measurement of a journal's performance is the "impact factor" (IF), the average number of times articles from the journal published in the past two years have been cited in the current year. The IF for the GRIR in January 2012 is equal to 0.733 and the review ranks 41 among 74 business finance journals. The ready accessibility of the IF and the lack of other well-known quality indicators have rapidly contributed to the attribution of IF as an indicator of journal quality. In this context, it is important to emphasise the unique role of the review, which serves as a catalyst for the study of risk and insurance matters from different perspectives, a role defined and still assumed by The Geneva Association. Therefore, it is not surprising to observe a low level of citations of papers published recently in the review. ${ }^{2}$

\footnotetext{
${ }^{1}$ See Outreville (2010).

${ }^{2}$ The calculation of the IF is biased by many factors and can be manipulated. One very crude way to do so is by requesting author self-citation or citations of papers published in the review (see Dong et al., 2005). Neuberger and Counsell (2002) reported how one journal editor suggested the inclusion of more references to that journal.
} 
In this volume, papers published in the review since 2005 have been quoted only three times and in only two papers. ${ }^{3}$ Most of the citations originate from a group of highly ranked economic journals (American Economic Review, Quarterly Journal of Economics and Journal of Political Economics), followed by a group of four journals specialised in mathematical and quantitative finance. ${ }^{4}$ One reason is stated in the mission of the review, that is, to publish "new and innovative ideas". Volume 36 (2011) of the GRIR illustrates this objective with papers dealing with surety bonds and weather risk derivates. The publication of the annual EGRIE keynote address is also an opportunity to publish original papers drawing ideas from the economic literature.

Nevertheless, several papers published in this volume of the GRIR provide direct insights to the insurance literature looking at the asymmetric information problems in insurance markets and are of particular relevance for insurers and for the understanding of insurance markets. The issue of adverse selection, asymmetric information and moral hazard is examined in the context of the cancer insurance market. The wealth effect of demutualisation is also examined for the property-liability business, which has in the past received relatively little attention in the review.

This paper presents an overview of the major topics explored in ten papers published in GRIR 2011. The next section will focus on the analysis of specific markets or products (surety bonds and weather risks). The subsequent section will review two papers dealing with decision-making under uncertainty. The section following it will review papers dealing with asymmetric information in insurance markets and another section will discuss research in finance and actuarial science applied to risk management. The penultimate section looks at the problem of demutualisation and performance of property-liability insurance companies. The last section presents brief remarks to conclude this survey of GRIR 2011.

\section{The analysis of original markets and products}

\section{Surety bonds}

A surety bond is a promise to pay one party (the obligee) a predefined amount in the case a contractor (the second party or the principal) fails to meet the terms of a contract. In traditional insurance, the risk is transferred to the insurance company. In surety bonding, the risk remains with the principal. Surety bonds are an important risk mitigation tool. ${ }^{5}$

The paper by Wambach and Engel ${ }^{6}$ contributes to the literature on surety bonds by looking at the problem of abnormally low tenders as contractors who are more likely to go bankrupt. As explained by the authors, there is a failure rate of almost one out of

\footnotetext{
${ }^{3}$ This corresponds to the date when the change of name from The Geneva Papers on Risk and Insurance Theory to The Geneva Risk and Insurance Review took place.

${ }^{4}$ When counting the number of citations by journals, Econometrica and the Journal of Risk and Insurance rank second and third, respectively, after the American Economic Review.

${ }^{5}$ For a definition, see, for example, Rejda (2011, Chapter 27).

${ }^{6}$ Wambach and Engel (2011).
} 
four contractors in the United States. During a procurement process, a low winning tender can be bad news for the procurement agency if the winning contractor goes bankrupt before finishing the project. To deal with the problem, governments have introduced surety bonds in public procurement.

This paper examines the two cases of fair and unfair pricing strategies for the surety bonds. In line with the insurance literature, fair pricing leads to an efficient outcome, in the sense that the surety company always finishes the project. The authors even show that if there is overinsurance, this remains efficient as long as the surety bond is priced fairly. Full insurance is still optimal if surety bonds are priced with a small fixed fee. This result is interesting as usually in the insurance literature, marginally unfair prices (or premiums) lead to partial insurance.

If the surety is priced unfairly with a large risk loading, then the bidding function (i.e. contractor's bids) decreases in wealth. Potential contractors with low wealth have to pay a high risk premium and thus submit higher bids compared to contractors with larger wealth. Contractors with a higher risk of bankruptcy will not bid less than a contractor with a lower risk of bankruptcy. More solvent contractors are more likely to win, thus the problem of abnormally low tenders is alleviated. Thus the agency is more likely to end up either with those contractors who never go bankrupt or with those for whom the surety company pays the bond in case of bankruptcy.

\section{Weather risk hedging}

Weather derivatives were first introduced in 1997 to help firms manage their weatherrelated risk exposure. Since that time, the market has expanded rapidly into a flourishing over-the-counter (OTC) market. ${ }^{7}$ The first weather transactions took place in 1997 between Enron and Koch Industries. In 1999, the Chicago Mercantile Exchange (CME) took weather derivatives a step further and introduced exchangetraded weather futures and options on futures. OTC weather derivatives are privately negotiated, individualised agreements made between two parties. CME weather futures and options on futures are standardised contracts traded publicly on the open market in an electronic auction-like environment, with continuous negotiation of prices and complete price transparency. ${ }^{8}$

The paper by Yang et al. ${ }^{9}$ analyses weather risk hedging efficiency in three European countries using weather derivatives traded at the CME and explores the potential of weather derivatives as a new investment asset to further diversify investors' portfolios.

The sample of this research consists of 40 European cities in three countries, that is, Spain, United Kingdom and Germany. The results document that the CME European weather contracts are generally effective in hedging the temperature risk in the three European countries. But the paper also explores the potential of weather derivatives as an alternative investment instrument to further diversify investors' portfolios. Zero or

\footnotetext{
${ }^{7}$ According to the Weather Risk Management Association (WRMA at www.wrma.org), the market grew by 20 per cent in the period 2010-2011.

${ }^{8}$ See Barrieu and Scaillet (2010).

${ }^{9}$ Yang et al. (2011).
} 
little correlation among international weather indexes and stockmarket indexes indicates that weather derivatives should be an efficient investment diversifier. This research provides important insights into both weather risk hedgers and investors.

\section{Decision-making under risk and uncertainty}

\section{On the underestimation of the precautionary effect in discounting}

Because financial markets do not provide any pricing rule for very long-term projects, there is a tendency among economists and decision-makers to discount the far-distant future at the lowest possible rate. Christian Gollier has discussed the recent literature on discounting in previous papers, ${ }^{10}$ and the presentation of the author at the $37^{\text {th }}$ Seminar of the European Group of Risk and Insurance Economists (EGRIE) proposes an empirical evaluation based on a sample of 190 countries over the period 1969-2010. ${ }^{11}$

Uncertainty about the growth rate of the economy should play an important role in the determination of the level of the discount rate. The paper is based on previous theoretical literature (the Ramsey rule), which shows that the discount rate has three components. ${ }^{12}$ The first one is the rate of pure preference for the present; the second one is a positive wealth effect; and the third component is a negative precautionary effect. Because future consumption is uncertain, prudence should induce us to invest more for the future by reducing the discount rate.

The paper shows that the socially efficient rate is the difference between a wealth effect and a precautionary effect of economic growth. The author considers that the history of shocks on country-specific economic growth rates provides information about the long-term uncertainty faced within each country. He estimates the uncertainty affecting growth by the standard deviation of the growth rate of consumption over the period under study.

Using time series, the discount rate is of the same order of magnitude (i.e. 3.4 per cent on average) for developed countries like the United States, France, Germany and the U.K. For Japan, the mean growth rate and the volatility have been larger, yielding a discount rate of approximately 4.5 per cent. The picture is quite different for emerging countries in Asia, with China showing a discount rate as large as 14.82 per cent. At the opposite end of the spectrum, African countries are experiencing negative discount rates. The average discount rate among the 190 countries is 2.5 per cent but the important differences among the countries make it difficult to draw general conclusions about the discount rate.

Using cross-section data, the author estimates a small discount rate between 0.67 per cent per year and 1.59 per cent when data is population-weighted to take into account the presence of China. This result is significantly lower than the recommended discount rate in the existing literature that varies between 3 and 6 per cent.

\footnotetext{
${ }^{10}$ See, for example, Gollier (2009).

${ }^{11}$ Gollier (2011).

12 Ramsey (1928).
} 


\section{More on discounting and information acquisition}

Economic agents may discount the short-term events at a relatively higher rate than the long-term events. Discount rate gathers all the psychological motives of the agent's investment choice, such as anxiety, confidence or impatience. ${ }^{13}$

The paper by Chemarin and Orset $^{14}$ investigates the impact of information acquisition on the behaviour of economic agents. Investing in technological innovations generates uncertainty about the future returns, as well as about the damages that such innovations could involve and about the cost to pay in case of troubles. Information acquisition could be viewed as precautionary efforts to limit the potential damages that the project could have on people's health or on the environment. The authors provide interesting and relevant examples such as the case of asbestos, the pharmaceutical and chemical industries or innovations in nanotechnologies.

To reduce this uncertainty, the agent has the opportunity to acquire information, or not. A classic view is that decision-makers choose not to acquire information in order to avoid additional costs. ${ }^{15}$ The authors offer a new explanation by showing that an economic agent does not refuse free information but may under certain conditions remain strategically ignorant or acquire less information than possible. Moreover, the information refusal depends not only on the cost of this information but also on the degree of the precision of that information. By introducing costly information linked to information precision, the agent will acquire information unless the cost exceeds direct benefits.

The authors also analyse important implications for regulators such as the way in which liability rules influence the agent's decision to acquire information or the level of the penalty if an accident occurs. Concerning the first point, a strict liability rule does not appear to be a useful tool to give an incentive to an agent, regardless of his preferences, to acquire information. On the contrary, the negligence rule, may lead the agent to behave in a more precautionary way. In case of a penalty, a direct implication would be the desire of the agent to subscribe an insurance contract to cover potential damages linked to his activity. This remains an interesting potential research area.

\section{Asymmetric information in insurance markets}

\section{Asymmetric information in the cancer insurance market}

While cancer insurance is only recently gaining popularity in the United States, it has been a successful product in Japan for over 20 years. In Japan, approximately onequarter of the population own cancer insurance. ${ }^{16}$ Cancer insurance conceptually is very simple and supplements existing health insurance policies or income.

In economics and contract theory applied to insurance, some form of asymmetric information does exist and while the possibility of moral hazard playing a role in this

\footnotetext{
${ }^{13}$ See Frederick et al. (2002).

${ }^{14}$ Chemarin and Orset (2011).

${ }^{15}$ Carrillo and Mariotti (2000).

16 Bennett et al. (1998).
} 
market is only minor, we can accordingly infer that this is evidence of adverse selection, that is, those who purchase extended cancer insurance contracts are the ones with a higher probability of contracting cancer.

The paper by Wang et al. ${ }^{17}$ investigates the problem of asymmetric information in Taiwan's cancer insurance market. Problems in this market have received little attention compared to other insurance markets. The authors are relying heavily on papers looking at asymmetric information in the health insurance or automobile insurance markets.

Through the survey data, the authors find evidence of adverse selection existing in this market by testing the conditional correlation between risk and coverage. After controlling for the information that the insurance company holds, the residual correlation between the risk and coverage can be inferred as evidence of asymmetric information. Furthermore, they find that the individual's family cancer history contains valuable information that helps predict the willingness to purchase cancer insurance.

They conclude that the regulation that prevents insurance companies from using valuable information such as a family's cancer history is worth further discussion since a change in these regulations could lead to a gain in social welfare.

\section{More on asymmetric information: the principal-agent problem}

The principal-agent problem arises under conditions of incomplete and asymmetric information when an agent, because of his behaviour, imposes an externality on the principal, who, not surprisingly, will want to influence the agent's actions. Because the insurance contract cannot be directly contingent on such behaviour, it is designed to mitigate the externality that the agent imposes on the insurance company.

In the brokerage industry, an insured (the principal) hires a broker (the agent) to arrange for insurance coverage for a certain potential loss. Therefore, contrary to the traditional problem, the principal is the risk-averse party while the agent is riskneutral. The paper by $\mathrm{Hau}^{18}$ studies this particular problem. The important question that arises from this problem is related to the shape of the optimal reward function for the broker. To induce the risk-neutral insurance broker to exert costly effort to search for appropriate insurance coverage to reduce the risk, the insured should impact the broker's payoff function so that the broker will act as if it is risk-averse. The purpose of the paper is to demonstrate that, theoretically, the reward function should take into account the behaviour of the broker. In reality, as stated by the author, this is seldom observed in insurance brokering.

\section{Research in finance and actuarial science applied to risk management}

The paper by Trufin et al. ${ }^{19}$ discusses risk measures for insurance portfolios, which are derived from actuarial ruin theory, namely the value-at-risk (VaR) concept and the

\footnotetext{
${ }^{17}$ Wang et al. (2011).

${ }^{18}$ Hau (2011).

${ }^{19}$ Trufin et al. (2011).
} 
600

Tail-VaR. VaR has emerged as the standard tool for measuring financial risks, and the past decade has witnessed a surge in the effort that financial market participants devote to risk management. ${ }^{20}$

Standard option pricing literature relies on the hypothesis that the dynamics of the underlying assets are independent of the hedging strategy. The paper by Agliardi and Andergassen $^{21}$ extends the analysis of feedback effects of dynamic hedging strategies on the underlying assets to the case of fixed costs of transactions. Once transaction costs are taken into account, continuous portfolio re-hedging is no longer an optimal strategy. Derman and Taleb $^{22}$ previously demonstrated that one cannot hedge continuously. Discrete hedging causes the portfolio to become risky before the next rebalancing. In addition to the impossibility of continuous hedging, transaction costs at each discrete re-hedging impose a cost that make an options position worth less than the Black and Scholes value.

In another paper by Quittard-Pinon and Randrianarivony, ${ }^{23}$ the Black and Scholes framework is extended to a more general case allowing for stochastic interest rates and jumps. In this paper, the impact of market risk and actuarial risk is analysed through the "fair value" of insurance risk charges within a life insurance portfolio.

These results derived from the field of finance can be of interest for applications in insurance portfolio management.

\section{Demutualisation and performance of property-liability insurance companies}

Demutualisation refers to the conversion of a mutual insurer to a stock company. It has become a very timely research topic given the conversions of several large life insurance companies in the United States. ${ }^{24}$ Results present evidence that the outperformance in stock returns is mainly attributable to improvement in postdemutualisation operating performance. The combined results of under-pricing and long-term performance suggest that the wealth of policyholders who choose stock rather than cash or policy credits is not harmed by demutualisation.

The paper by Chen et al. ${ }^{25}$ investigates whether the conversion of U.S. propertyliability insurers improves their efficiency performance before and after the conversion. Conversions are examined over the period 1993-1998. They utilise two data envelopment analysis methods, the value-added approach and the financial intermediary approach. The financial intermediary approach considers overall financial strengths more, whereas the value-added approach focuses more on underwriting. They also conduct regression analyses to examine efficiency and productivity changes between the converting insurers and a subset of control insurers.

\footnotetext{
${ }^{20}$ In the previous volumes of the GRIR, several papers, not mentioned by the authors, have looked at the insured's VaR constraint in the optimal insurance decision.

${ }^{21}$ Agliardi and Andergassen (2011).

${ }^{22}$ In their paper, Derman and Taleb (2005) have shown that dynamic hedging is neither strictly required nor strictly necessary for plausibly valuing options.

${ }^{23}$ Quittard-Pinon and Randrianarivony (2011).

${ }^{24}$ See Lai et al. (2008).

${ }^{25}$ Chen et al. (2011).
} 
The evidence shows that converting insurers experience larger gains in cost efficiency and total productivity change than mutual control insurers before conversion. In addition, the empirical results indicate that converting insurers improve efficiency after conversion. These results are robust with respect to both the value-added and the financial intermediary approaches.

\section{Discussion and conclusion}

Among the papers published in this volume of the GRIR, some provide direct insights to the insurance industry by demonstrating, for example, the role of asymmetric information in the cancer insurance market or the effect of demutualisation on the performance of the property-liability insurance industry. The issue of adverse asymmetric information and moral hazard is of particular relevance for insurers and the proper functioning of insurance markets. The proper disclosure of information is also relevant in many aspects of attitude towards risk and insurance purchase. The investigation of the impact of information acquisition on the behaviour of economic agents is in this line of research.

All the perspectives on decision-making under uncertainty or decision-making under ignorance are also important issues with direct applications not only to insurance, but also to other sectors of the financial services market. Uncertainty about the growth rate of the economy plays an important role in the determination of the level of the discount rate.

Most importantly, The Geneva Association, through publications like the GRIR, serves as a catalyst for progress in the understanding of risk and uncertainty and the publication of new topics applied to insurance matters. Two papers on the efficiency of surety bonds and on the role of weather risk instruments are examples of this claim.

Finally, many of these papers highlight how applied research derived from the fields of economics, finance or actuarial science could help understand the impact of market risks and have important implications for the insurance industry.

\section{References}

Agliardi, E. and Andergassen, R. (2011) '(S,s)-adjustment strategies and hedging under Markovian dynamics', Geneva Risk and Insurance Review 36(2): 112-131.

Barrieu, P. and Scaillet, O. (2010) 'A primer on weather derivatives', in A.J. Filar and A. Haurie (eds.) Uncertainty and Environmental Decision Making: A Handbook of Research and Best Practice, International series in operations research \& management science, New York: Springer, pp. 155-176.

Bennett, C.L., Weinberg, P.D. and Lieberman, J.J. (1998) 'Cancer insurance policies in Japan and the United States', Western Journal of Medicine 168(1): 17-22.

Carrillo, J.D. and Mariotti, T. (2000) 'Strategic ignorance as a self disciplining device', Review of Economic Studies 67(3): 529-544.

Chemarin, S. and Orset, C. (2011) 'Innovation and information acquisition under time inconsistency and uncertainty', Geneva Risk and Insurance Review 36(2): 132-173.

Chen, L.R., Lai, G.C. and Wang, J.L. (2011) 'Conversion and efficiency performance changes: Evidence from the U.S. property-liability insurance industry', Geneva Risk and Insurance Review 36(1): 1-35.

Derman, E. and Taleb, N.N. (2005) 'The illusions of dynamic replication', Quantitative Finance 5(4): $323-326$. 
Dong, P., Loh, M. and Mondry, A. (2005) 'The “Impact Factor” Revisited', Biomedical Digital Libraries, December. This article is available from http://www.bio-diglib.com/content $/ 2 / 1 / 7$.

Frederick, S., Loewenstein, G. and O'Donoghue, T. (2002) 'Time discounting and time preference: A critical review', Journal of Economic Literature 40(2): 350-401.

Gollier, C. (2009) Should we discount the far-distant future at its lowest possible rate?, Economics Discussion Papers, No 2009-7, Kiel Institute for the World Economy. http://www.economics-ejournal.org/economics/ discussionpapers/2009-7.

Gollier, C. (2011) 'On the underestimation of the precautionary effect in discounting', Geneva Risk and Insurance Review 36(2): 95-111.

Hau, A. (2011) 'Optimal brokerage commissions for fair insurance: A first order approach', Geneva Risk and Insurance Review 36(2): 189-201.

Lai, C.G., McNamara, J.M. and Yu, T. (2008) 'The wealth effect of demutualization: Evidence from the U.S. property-liability and life insurance industries', Journal of Risk \& Insurance 75(1): 125-144.

Neuberger, J. and Counsell, C. (2002) 'Impact factors: Uses and abuses', European Journal of Gastroenterol Hepatol 14(3): 209-211.

Outreville, J.F. (2010) 'The Geneva Risk and Insurance Review 2009: In quest of behavioural insurance', Geneva Papers on Risk and Insurance 35(3): 484- 497.

Quittard-Pinon, F. and Randrianarivony, R. (2011) 'Impacts of jumps and stochastic interest rates on the fair costs of guaranteed minimum death benefit contracts', Geneva Risk and Insurance Review 36(1): $51-73$.

Ramsey, F.P. (1928) 'A mathematical theory of savings', Economic Journal 38(152): 543-559.

Rejda, G.E. (2011) Principles of Risk Management and Insurance, Pearson Education, Prentice-Hall, 11 th edition.

Trufin, J., Hansjoerg, A. and Denuit, M.M. (2011) 'Properties of a risk measure derived from ruin theory', Geneva Risk and Insurance Review 36(2): 174-188.

Wambach, A. and Engel, A.R. (2011) 'Surety bonds with fair and unfair pricing', Geneva Risk and Insurance Review 36(1): 36-50.

Wang, K.C., Peng, J.L., Sund, Y.Y. and Chang, Y.C. (2011) 'The asymmetric information problem in Taiwan's cancer insurance market', Geneva Risk and Insurance Review 36(2): 202-219.

Yang, C.C., Li, L.S. and Wen, M.M. (2011) 'Weather risk hedging in the European markets and international investment diversification', Geneva Risk and Insurance Review 36(1): 74-94.

\author{
About the Author \\ Jean-François Outreville is Adjunct Professor of Risk Management and Insurance in \\ the Department of Finance at HEC Montreal in Canada. He is also Research Fellow \\ at International Centre for Economic Research, Turin (Italy).
}

